University of Chicago Law School

Chicago Unbound

Journal Articles

Faculty Scholarship

1999

\title{
The (Limited) Role of Regulatory Harmonization in International Goods and Services Markets
}

Alan O. Sykes

Follow this and additional works at: https://chicagounbound.uchicago.edu/journal_articles

Part of the Law Commons

\section{Recommended Citation}

Alan O. Sykes, "The (Limited) Role of Regulatory Harmonization in International Goods and Services Markets," 2 Journal of International Economic Law 49 (1999).

This Article is brought to you for free and open access by the Faculty Scholarship at Chicago Unbound. It has been accepted for inclusion in Journal Articles by an authorized administrator of Chicago Unbound. For more information, please contact unbound@law.uchicago.edu. 


\title{
THE (LIMITED) ROLE OF REGULATORY HARMONIZATION IN INTERNATIONAL GOODS AND SERVICES MARKETS
}

\author{
Alan O. Sykes*
}

\begin{abstract}
With the conclusion of the Uruguay Round and its agreements relating to technical barriers, much attention has been devoted to the possibility of harmonizing international regulatory policies to reduce the impediments to commerce that result from regulatory heterogeneity. This paper argues that, as a normative matter, harmonization is inferior to a legal system that tolerates regulatory differences subject to legal constraints, and that relies on mutual recognition where appropriate (the exception to this claim being matters of technical compatibility between products). Related, as a positive matter, harmonization will often lack any political constituency and thus instances of true harmonization will be rare. To develop these claims, the paper carefully elucidates the unnecessary trade impediments that may result from regulatory heterogeneity, and shows how measures short of harmonization can usually address them adequately.
\end{abstract}

\section{INTRODUCTION}

The traditional instruments of protectionism (tariffs and quotas) are increasingly unimportant in the international economy, owing to the success of trade liberalizing accords such as the WTO/GATT, NAFTA and the Treaty of Rome. The attention of the trading community has accordingly shifted to various 'nontariff barriers' to trade, which remain important in many goods sectors and lie at the heart of impediments to international trade in services. Among the most important sources of such impediments is variation among nations in their domestic regulatory policies - what I term 'regulatory heterogeneity'.'

- Frank \& Bernice J. Greenberg Professor of Law, University of Chicago Law School, The University of Chicago, 1111 East 60th Street, Chicago, IL 6063, USA. I have benefited from comments at a Columbia University conference on trade issues for the next century, and from members of the editorial board.

1 Throughout this paper, I use the term 'regulation' as it is used in the WTO/GATT agreements, to refer to policies promulgated by governments with which compliance is mandatory. 'Standards', with which compliance is voluntary and which may result from either govemment or private sector activity, are to be distinguished. Nevertheless, much of what I have to say about regulations can also be applied to standards issues. For a more complete discussion, see A. O. Sykes, Product Standards for Internationally Integrated Goods Markets (Brookings 1995). 
Regulatory heterogeneity in the international economy can increase the costs of exporting firms and impede trade in both goods and services. If these trade impediments can be reduced without violence to legitimate regulatory objectives, global economic welfare will increase just as it does when tariffs, quotas and other traditional trade restrictions are eliminated. ${ }^{2}$ Yet national regulators are often reluctant on their own to make allowances for the trade impact of their policies, sometimes for high-minded reasons and other times for not so high-minded reasons. The inevitable result has been pressure for international accords to address the trade effects of regulatory heterogeneity, and many such accords now exist.

The possible international responses to regulatory heterogeneity may be divided into three generic categories. First, the trading community can allow national (and sometimes sub-national) regulators to regulate all goods or services sold within their jurisdiction, tolerating a considerable degree of heterogeneity in the resulting policies, while concurrently imposing a number of constraints on those policies to reduce their adverse impact on trade. These constraints can include notice and transparency requirements, nondiscrimination requirements, least restrictive means requirements, and the like. This type of response I will term 'policed decentralization'.

Second, the international community can exempt imported goods and services from the regulations of the importing nation while requiring exporters to comply with applicable regulations in their home country. This approach also tolerates the persistence of regulatory heterogeneity across nations, and reduces its trade impact by ensuring that each firm need comply with only one set of regulations (those of its home country) regardless of the number of markets in which it sells. Such a policy is known as 'mutual recognition'.

Third, the international community can undertake to address regulatory heterogeneity by negotiating an end to it - a compact requiring all nations to follow the same substantive regulations. And once differences in national regulatory policies are eliminated, the trade effects of those differences necessarily evaporate as mutual recognition can be extended as a matter of course. This last option I will term 'regulatory harmonization'.

As a terminological preliminary, the use of the term 'harmonization' in this paper does not fully accord with its meaning elsewhere. For example, David Leebron has defined harmonization as 'making the regulatory requirements or governmental policies of different jurisdictions identical, or at least more similar'. This definition is much too broad for my purposes, for all three

2 Indeed, the elimination of regulatory barriers to trade may often generate greater welfare gains than the elimination of other trade barriers. A. O. Sykes, 'Regulatory Protectionism and the Law of Intemational Trade', Univ, of Chicago L. Rev. (forthcoming).

${ }^{3}$ D. Leebron, 'Lying Down with Procrustes: An Analysis of Harmonization Claims', in J. Bhagwati and R. Hudec (eds), Fair Trade and Harmonization: Prerequisites for Free Trade? Vol. 1 (MIT Press: 1996), 41-117, at 43. Here, 'harmonization' is used in a strong sense to capture international agreements that would homogenize regulatory policy and largely eliminate national differences. 
options that I address - policed decentralization, mutual recognition, and harmonization as here defined - have the ability to make regulatory policies 'more similar' in certain respects. My enterprise involves a careful effort to distinguish these techniques, and cannot tolerate confusion among them.

Likewise, the focus here is on the kinds of regulatory heterogeneity that create actual or potential impediments to trade at the border. By an 'impediment', I mean a measure that increases the costs to foreign firms of serving a particular export market, and wish to distinguish regulatory differences across nations that may raise a policy concern of a different sort. In particular, it is sometimes asserted that differences in environmental policies across nations, or in labor standards, or in competition policy, give certain firms an unfair cost advantage in trade at the expense of broader social welfare or social justice concerns. Regardless of the merits of such claims, the purportedly objectionable trade impact of such differences lies not in the compliance burden imposed on foreign firms, but on the cost advantage conferred on domestic firms by regulatory laxity in some nations. The issues there are different, as they involve concerns about cross-boundary externalities, 'races to the bottom', and so forth, which I do not intend to address. ${ }^{4}$

In many ways, regulatory harmonization might seem the most straightforward solution to the trade impediments created by regulatory heterogeneity. Unlike policed decentralization, harmonization altogether eliminates the need for firms to comply with different sets of regulations, and the associated costs. Unlike mutual recognition, regulatory harmonization assures all importing nations that goods and services produced abroad meet their mutually agreed upon regulatory objectives.

Interestingly, however, regulatory harmonization is infrequent at the global level. This paper asks why, and further inquires whether the absence of greater regulatory harmonization is unfortunate.

Because I am posing these questions at a high level of generality without limitation to particular goods or service sectors, the analysis is subject to inevitable caveats and exceptions. But the general lessons are clear. From a normative standpoint - that is, from the standpoint of someone concerned about the maximization of global economic welfare - it is very much the exceptional case in which international regulatory harmonization is the best option. Most importantly, it is often socially productive to respect differences in national preferences regarding regulatory policy. Where those preferences

4 Much of the literature on these issues nevertheless reaches a conclusion similar to mine - that intemational harmonization is neither necessary nor desirable to avoid undue laxity in environmental, labor or competition policies. See generally J. Bhagwati and R. Hudec (eds), Fair Trade and Harmonization: Prerequisites for Free Trade?, Vols. 1-2 (MIT Press: 1996), especially the papers by Bhagwati and Srinivasan, and by Brown, Deardorff, and Stern; R. L. Revesz, "Rehabilitating Interstate Competition: Rethinking the "Race to the Bottom" Rationale for Federal Environmental Regulation', 67 N.Y.U. L. Rev. 1210 (1992). For a contrary view, see D. C. Esty, 'Revitalizing Environmental Federalism', 95 Mich. L. Rev. 570 (1996). 
reflect differences in risk tolerance, differences in incomes, or differences in geography, for example, regulatory heterogeneity is desirable, other things being equal. Further, once put in place, internationally harmonized regulations may be more difficult to adapt to new information and technologies. Regulatory heterogeneity will exist in an ideal world, therefore, to a considerable extent.

But heterogeneity would nonetheless be limited in an ideal world to those differences in regulatory policy that reflect 'legitimate' differences among nations. Regulatory heterogeneity driven by protectionist capture, by bureaucratic indifference or by information failures would not survive, and the trade effects of 'legitimate' regulatory heterogeneity would be minimized. Further, there may arise circumstances in which even 'legitimate' heterogeneity is not worth its cost because its benefits are small and its trade effects great.

It is my thesis that sound principles of policed decentralization, coupled with appropriate agreements to afford mutual recognition, can achieve these ideals; harmonization is not needed and is often undesirable. This normative claim provides the germ of a positive claim as well. In particular, although I will stipulate that international political equilibria rarely achieve the normative ideal, the absence of any compelling normative case for harmonization provides some basis to doubt that it will be pursued very often, a notion seemingly borne out by experience.

Section 1 elaborates in some detail the ways that regulatory heterogeneity can impede trade in goods and services. Section 2 then considers the causes of regulatory heterogeneity, which bear importantly on whether the international community should undertake to do anything about it. Section 3 discusses the extent to which policed decentralization and mutual recognition will eliminate the trade 'impediments' that result from regulatory heterogeneity, and identifies the types of impediments that will remain. Section 4 inquires whether regulatory harmonization is a desirable way to address these remaining impediments, and whether it is likely to occur.

\section{THE COSTS OF REGULATORY HETEROGENEITY}

At some level it is obvious that the need to comply with different sets of regulations in different markets can increase the costs of doing business. Nevertheless, it is useful to articulate the ways in which regulatory heterogeneity can increase costs, as the various kinds of increased costs require different strategies for remediation.

Inherent differences in compliance costs due to differences in regulatory stringency

Trivially, some regulations are more costly to comply with than others, even when they are aimed at the same general regulatory objective. The cost per vehicle to reduce auto emissions, for example, will increase as the permissible 
level of emissions declines. The opportunity costs of the funds required to be held on reserve by commercial banks will rise as the fractional reserve requirement increases.

These types of costs are not really costs of regulatory heterogeneity per se, but result from the fact that some regulations are more stringent than others. Were heterogeneity in this sense to be eliminated, the total costs to firms of regulatory compliance might increase, decrease, or remain the same depending on whether the international community converged on more stringent, less stringent, or intermediate levels of regulatory requirements.

Likewise, although firms may lament the fact that some of their markets require them to comply with more stringent regulatory requirements than others, differences in the stringency of regulations do not necessarily disadvantage foreign firms relative to domestic firms. It is only when compliance costs per unit of output are higher for foreign firms than for domestic firms that the 'playing field' tilts toward domestic producers.

This last observation suggests a division of cases that is quite important. At times, regulatory heterogeneity affects foreign and domestic suppliers equally, imposing greater or lesser compliance costs in accordance with the stringency of the regulation without regard to the origin of the regulated good or service. In this group of cases, regulatory heterogeneity is not really a 'trade problem' at all. To be sure, the wisdom of regulatory policy in a given country may be hotly debatable, and it may be that one or more countries is over-regulating and imposing socially unproductive costs on all firms (and consumers) in its market. But if foreign firms face the same compliance costs as domestic firms, comparative advantage will dictate who succeeds in the market and who fails. Likewise, trade accords are pertinent only to the degree that they may provide a forum for persuading nations that over-regulate to change their ways.

In other cases, however, regulatory differences may impose greater costs on foreign firms than on domestic firms. It is here that trade is more directly implicated. In the remainder of this section, therefore, I focus on costs of regulatory heterogeneity that tend to fall more heavily on foreign suppliers.

\section{Added requirements for foreign firms}

Obviously, regulations that apply exclusively to foreign firms will raise their costs relative to the costs of their domestic competitors. Where the regulatory regime is discriminatory in a way that disfavors foreign suppliers, therefore, trade is directly affected just as if the importing nation had employed a tariff or some other conventional protectionist instrument.

\section{Costs of 'surprise'}

Often, firms must make investments in new capital or retooling to comply with new regulations. Even where these costs are the same for domestic and 
foreign firms, greater advance notice of impending regulatory changes can confer a competitive advantage. Firms with more advance notice may be able to serve the regulated market sooner than others, affording them at least a transitory period of exclusive access. And, where economies of scale are important, this first mover advantage may translate into a long-term competitive edge. Because domestic firms tend to be better informed about and more involved in their own political systems than foreign firms, the costs of regulatory 'surprise' seem likely to fall more heavily on foreign firms.

\section{Redundancy costs}

Putting discrimination and surprise in regulatory policy to one side, different nations may nevertheless pursue their regulatory objectives in different ways. Country A may ensure that meats are safe for consumption by testing for bacteria and other residues after animals are slaughtered. Country B may pursue the same objective by requiring certain procedures to be followed during the slaughtering process. As another example, country A may undertake to ensure the solvency of its banks by requiring considerable levels of capital investment to cushion against portfolio losses (capital adequacy regulation). Country $B$ may pursue the same objective by regulating the riskiness of its banks' portfolios directly.

When firms do business in different countries, each country may require them to obey its regulations without modification. As a result, firms can become subject to redundant regulatory requirements that increase their costs of doing business without being necessary to the attainment of regulatory objectives. To return to the examples above, meat packing plants in country A may become subject to the slaughtering requirements of country $B$, even though post-slaughter testing by country $A$ is enough to ensure the wholesomeness of the meat. The bank of country $A$ that opens a branch in country B may become subject to the asset portfolio regulations of country $B$, even though the capital adequacy regulations of country $A$ are enough to eliminate the solvency risks that concern the regulators of country B.

These unnecessary costs will not afflict firms that serve only one market, and thus tend to fall exclusively on firms that engage in international trade. Thus, regulatory redundancy tilts the 'playing field' and is properly considered a trade issue.

\section{Loss of scale economies and input economies}

Related, firms that become subject to different regulations may elect to sever their operations into separate components that need only comply with the regulations in one market. They will do so when this option is cheaper than incurring the costs of redundancy.

In some cases, this response to differences in regulatory approach across countries will result in little added cost. If the independent operations for 
each market are large enough to exhaust all pertinent scale economies, and if they can purchase their inputs as cheaply as operations situated elsewhere, then they can deliver goods or services just as cheaply as consolidated operations. The different regulatory approaches may entail different costs of compliance, of course, so that firms in high compliance cost countries will have to charge more for their output, but again there need be no trade issue domestic firms and foreign firms that serve each nation can be on an equal competitive footing.

But it is clear that establishing separate operations to serve different national markets will often increase unit costs considerably, even putting aside differences in regulatory compliance costs. Separate facilities may forfeit any number of scale economies in manufacturing, management, marketing, risk diversification, and the like. Additionally, when firms can only avoid redundant regulations by establishing operations within the territories of each regulatory jurisdiction, they may be forced to pay considerably higher prices for some of their inputs. Whether the input is a live animal, a trained clerk, a data processing service, or something else, geographic constraints on production will prevent firms from locating themselves to take advantage of the most favorable input prices.

These increased costs that arise when firms must sever their operations to avoid regulatory redundancy also raise trade issues. Where scale economies are important, foreign firms may not be able to enter a market without doing so on a large scale, an option that may be quite unattractive due to its riskiness or to the existence of substantial capacity in that market already. And if avoiding regulatory redundancy requires firms to scatter their operations geographically, they may be at a disadvantage in securing their inputs.

\section{Information costs}

Putting aside the costs of regulatory redundancy or of establishing separate operations to avoid it, firms invariably must incur costs to learn about the regulatory systems in the various markets that they serve. They may need to translate regulations into another language, to hire lawyers to explain the regulations to them, and so forth. They may even incur substantial costs trying to identify who is in charge of regulating and where their regulations may be found in an accessible form.

These costs tend to be greater for foreign firms than for domestic firms because of language barriers that afflict foreign firms and because foreign firms may tend to be unfamiliar with the political and bureaucratic system abroad. Further, because the costs of learning about regulations may be largely independent of each firm's output, they tend to add more to the unit costs of firms that have a smaller market presence. This fact also tends to disadvantage foreign firms relative to domestic firms when the foreign firms have only a small presence in a given market. 


\section{Conformity assessment costs}

It is at times useful to distinguish the costs of complying with regulations from the costs of proving compliance to the satisfaction of regulators. The meat packing plant that sells to multiple markets may become subject to multiple inspections and added paperwork. The bank that serves multiple markets may become subject to additional bank examinations and audit requirements. These costs of demonstrating compliance with regulations are commonly known as costs of 'conformity assessment'.

Like the costs of learning about regulations, the costs of demonstrating conformity may be higher for foreign firms because of language barriers or because the required conformity assessment procedure necessitates dealings with an unfamiliar entity (such as a testing laboratory) in a foreign country. The unit costs of conformity assessment may also be greater for firms with a smaller presence in a market - where conformity assessment requires that a certain number of units of output be inspected, for example, or that a certain type of audit be performed, firms with larger output can spread the costs over a larger base, giving large domestic firms an advantage over smaller foreign firms.

Conformity assessment costs may disadvantage foreign firms for yet another reason. Just as substantive regulations may be redundant, so may the testing and certification necessary for conformity assessment. Suppose, for example, that country $A$ and country $B$ have identical regulations respecting the procedures by which animals are slaughtered. If both countries insist on inspections by their own inspectors, conformity assessment costs for a firm that serves both markets will be roughly twice those of a firm that serves only one, notwithstanding the absence of any substantive difference in the regulations, and notwithstanding the fact that a single inspection process may suffice to ensure compliance with regulations in both countries. A bank that must incur the cost of two separate audits might confront the same problem.

To conclude this section, I wish to be clear that when I use the term 'cost' above I do not mean to equate it with 'inefficiency', nor do I mean to suggest that any cost which burdens foreign firms more heavily is undesirable while any cost which burdens domestic and foreign firms equally is acceptable. As noted, regulations may be wasteful or foolish even if they are neutral in a trade sense. Conversely, regulatory heterogeneity may be defensible even when it is not neutral in a trade sense - the relatively greater burden on foreign firms may be unavoidable if some legitimate regulatory objective is to be attained. But as will become clear below, there are many ways in which the trade impact of regulatory heterogeneity can be reduced without sacrificing legitimate regulatory goals, and without the need for nations to reach agreement on precisely which set of substantive regulations is ideal. Put more strongly, the international community can eliminate most of the 
demonstrably undesirable trade impact of regulatory heterogeneity with measures that fall short of regulatory harmonization. The remaining costs of heterogeneity will then inhere in the decision by some nations to regulate more stringently. Before turning to that discussion, however, it is important to consider the reasons why regulatory heterogeneity may emerge in the first instance.

\section{THE CAUSES OF REGULATORY HETEROGENEITY AND THEIR IMPLICATIONS FOR POLICY}

Just as the different costs of regulatory heterogeneity will suggest different possibilities for remediation, so do the different reasons for regulatory heterogeneity suggest different responses by the trading community. Put simply, there is good heterogeneity and bad heterogeneity - the principal line is between heterogeneity that reflects honest differences in tastes and incomes and a few related factors, and heterogeneity that reflects indifference, inadequate information or capture. Heterogeneity that arises for the first set of reasons is not only acceptable but probably desirable as a policy matter. Heterogeneity driven by the second set of considerations is undesirable, and would be eliminated (or its effects eliminated) in an ideal world.

\section{Citizen tastes, incomes, and related factors}

The cultures and experiences of citizens in different societies will often lead them to assign different priorities to particular types of regulation. A nation in which insurance company failures or bank runs have been a problem may exhibit a stronger demand for prudential regulation of these financial institutions. A nation that has experienced a safety-related tragedy may exhibit greater demand for health and safety regulation of a particular sort. Likewise, national constituencies may differ in the extent to which they 'trust' markets to function well, and in their attitude toward government - those less comfortable with markets and more sanguine about government intervention may tend to prefer regulatory measures more often.

Related, average income and the income distribution will have considerable influence on citizen demand for regulation. Consider, for example, regulations relating to the safety or quality of products. Most forms of safety and quality regulation increase the costs to consumers of the regulated good. The willingness of consumers to bear these additional costs will tend to rise as per capita income rises, because safety and quality are typically 'normal goods'. That is, individuals with higher incomes prefer to spend more on safety and quality. More generally, for all varieties of regulations that increase the costs of goods or services for the ostensible purpose of protecting consumers or the broader society from some perceived risk, we might expect that wealthier countries will prefer a greater level of regulation, other things being equal. 
The desire of the citizenry for regulation will also be influenced in many cases by the income distribution. To take a simple example, consider two democratic societies in which majority approval or disapproval of regulatory proposals turns on the preferences of the 'median voter'. Both have the same per capita income, but one has an egalitarian income distribution, and the other a skewed distribution with a minority of wealthy individuals and a majority of less affluent individuals. By the hypothesis that health and safety regulations are 'normal goods', the median voter will desire a greater level of this type of regulation in the first society than in the second.

Tastes and incomes are not the only factors that drive reasonable differences in regulatory policy. A jurisdiction in an area prone to earthquakes or hurricanes may well adopt special building codes as a result. The climate and geography around Los Angeles warrants extra efforts to control auto emissions. Other examples can no doubt be offered.

When regulatory heterogeneity across nations responds sensibly to these differences across jurisdictions, there can be little quarrel with it, even if it disadvantages certain foreign firms. In many instances, heterogeneity arising for these reasons can be defended on efficiency grounds; in other cases, democratic legitimacy would appear to justify it, even if a compelling efficiency case cannot be made. Either way, there is little argument for breaking down regulatory differences across countries under these circumstances or for labeling those differences a 'trade problem'.

Equally clearly, however, not all manifestations of regulatory heterogeneity can be justified by taste and income differences, and even when they can, it may be possible to reduce the trade effects by structuring regulation in certain ways. It is thus important to consider the other reasons why regulatory differences may arise.

\section{Chance and information differences}

The evolution of regulatory policy across jurisdictions may to a considerable degree result from chance factors. To illustrate, the adoption of either the metric or imperial system of measurement was once a matter of royal decree. The differences between the systems have no apparent functional rationale, and cannot be said to respond to differences in tastes or preferences across nations. Rather, they seem to be a by-product of the development of independent and largely arbitrary commercial standards in once-isolated markets. The commercial effects of these arbitrary differences still persist in a variety of regulatory settings (building codes to name just one). ${ }^{5}$

Plausibly, many other international differences in regulatory policy have a

5 A. Krueger has recently suggested that the continued adherence of the United States to the imperial system of measurement is the most important standards-related problem for American competitiveness. See A. Krueger, Testimony Before the Subcommittee on Technology and Competitiveness, U.S. House of Representatives Committee on Science, Space and Technology (4 March 1992), 102 Congress, 2nd session. 
similar genesis. They respond not to any difference in the desires of the citizenry or of narrower political constituencies, but to the whim of the bureaucrat who drafts the regulation, or perhaps to an arbitrary convergence of local practices that might well have converged on a different focal point.

Related, regulatory differences may reflect the limited information of policy makers at the time that regulations are formulated. Regulators may simply be unaware of all of the technologies capable of performing a particular regulatory task or of achieving a particular regulatory objective. Likewise, they may have only a subset of the pertinent scientific evidence available on various risks that they seek to control.

Where regulatory heterogeneity is the product of chance factors or of the limited information available to regulators, it is unlikely to serve any useful function, and its attendant burdens on trade are likely to be counterproductive. If the particular details of regulation are a result of chance, alternative regulations can often achieve regulatory objectives just as effectively. If regulations are based on limited information, they may prove outmoded or unnecessary altogether when viewed in light of more complete information. In each case, a move toward greater uniformity of regulation, or at least toward lessening the trade effects of heterogeneity, will benefit the trading community as a whole.

Whether such moves will occur, of course, will depend on political factors. Firms that have sunk costs in complying with existing regulations will resist any changes that would wipe out their sunk investments, and may even see opportunities to disadvantage rivals by perpetuating regulations that are especially costly to them. This observation leads to the next set of reasons for regulatory heterogeneity, and the most malign - those relating to capture.

\section{Capture}

Much of the modern economic literature on regulation emphasizes how it serves the interests of the regulated industries or other narrow constituencies, rather than the interests of society at large. ${ }^{6}$ The essential idea, borrowed from the general lessons of public choice, is that well-organized and cohesive interest groups can influence the political process to promote their interests at the expense of poorly organized groups or groups whose members have divergent interests. Regulated industries, and sometimes workers in those industries, often have homogeneous interests on matters subject to regulation, and have a sufficient stake in them to become organized to influence the political process. The result is that regulation, notwithstanding the high-minded rhetoric that may accompany it, may serve primarily to transfer economic surplus to the constituency that demands it, often the regulated industry itself.

6 See, e.g., S. Peltzman, 'Toward a More General Theory of Regulation', 19 J. L. \& Econ. 211 (1976); G. Stigler, 'The Theory of Economic Regulation', 2 Bell J. Econ. \& Man. Sci. 3 (1971). 
Such capture can readily produce regulatory heterogeneity and associated impediments to international trade. Indeed, the creation of those impediments may be the primary goal of the constituency that favors regulation.

The easiest way to disadvantage potential competitors from other jurisdictions is to create regulatory burdens that apply exclusively to them. A meat sanitation regulation might provide for annual inspection of domestic packing plants, for example, but require that meat from other jurisdictions be tested batch-by-batch for residues. Even more transparently, meat from other jurisdictions might be subject to stringent residue requirements that do not apply at all to locally produced meat.

But discriminatory policies are by no means the only way to disadvantage potential competitors. To give some examples in the financial services area, regulations may require that banks, insurance companies and the like establish a substantial physical presence within the regulatory jurisdiction, ostensibly to ensure that regulatory oversight can be conducted effectively and to 'bond' the regulated firms to obey pertinent regulations out of fear for losing their sunk investments. Or regulators may restrict in various ways the right to open new branch offices, purportedly to prevent 'ruinous competition' with existing firms. These regulations may nominally apply to all firms equally. Yet, all of these restrictions can also be seen as entry barriers, designed to insulate existing firms from new competition by making it difficult or at least more expensive for new firms to begin or expand operations. The same may be said of regulations that require firms to make their activities within a jurisdiction financially independent of their activities elsewhere, thereby depriving them of scale economies or input economies.

Nominally non-discriminatory regulations can also be constructed to favor domestic firms by requiring the use of technologies, processes or ingredients in which domestic firms have a proprietary interest, or at least in which they have a cost advantage. The same strategy can be applied to favor domestic firms in the conformity assessment process. Thus, automobiles might be required to use a particular proprietary pollution control technology, or to incorporate some particular safety device that is not in use in any other country. 'Pasta' might be required to contain certain ingredients in certain proportions, favoring ingredients that are cheap and abundant locally. Conformity assessment might be required to be conducted at a particular domestic testing laboratory, where goods from particular firms are handled more expeditiously. Innumerable other illustrations might be offered.

The use of regulations and associated conformity assessment requirements for the purpose of disadvantaging rival firms is obviously unproductive from a societal standpoint, much like the use of traditional instruments of protection such as tariffs. Indeed, regulatory barriers may be even more pernicious, as they may cause firms to waste resources on uneconomic methods of production to comply with regulations - tariffs, at least, leave all 
firms free to minimize costs as best they can. Thus, the international community would do well to ferret out this behavior as best it can and eliminate it.

Equally clearly, however, this type of unproductive activity may be difficult to eliminate as a political matter. By hypothesis, it results from the capture of the regulatory process by well-organized interest groups, and those groups may be expected to resist pressures for change fully as vigorously as they pressed for favorable regulation in the first instance. Indeed, resistance to change may be even more vigorous where change would threaten the returns to sunk investments. But it is important not to be too pessimistic. Tariffs and quotas are also the product of capture (importcompeting producer interest groups prevailing over consuming interest groups), and the world has seen much progress toward their elimination as noted earlier. Evidently, exporter interest groups favoring the liberalization of markets abroad are often able to persuade their national officials to sacrifice import protection to achieve it. These same forces should help drive the international community toward reducing some of the pernicious trade effects of regulatory capture as well. The hard question is how best to go about it.

\section{POLICED DECENTRALIZATION AND MUTUAL RECOGNITION}

Short of harmonizing regulatory policy across jurisdictions, the trading community has many options to address trade frictions that result from regulatory heterogeneity. Many of these options are already in place in various agreements, especially those relating to trade in goods. As I shall argue, these techniques can eliminate many of the undesirable obstacles to trade that result from regulatory differences.

\section{Policed decentralization}

As noted, 'policed decentralization' refers to a system in which regulators in different jurisdictions operate independently and may adopt different substantive regulations, but must do so subject to a number of constraints. Examples abound. The US federal system embodies a system of policed decentralization in which states exercise regulatory authority constrained by the dormant commerce clause and occasionally by federal statute. The European Union is also such a system, where Member States pursue their regulatory policies subject to the constraints of the Treaty of Rome as administered by the European Court of Justice, and to various directives from Brussels. NAFTA is yet another example, as is the WTO/GATT system both constrain the regulatory policies of member nations through agreements on technical barriers to trade, sanitary and phytosanitary measures, trade in services, and other subjects. Reduced to essentials, these systems suggest a handful of basic principles that reduce the adverse consequences for trade 
of regulatory heterogeneity while still allowing national regulators the freedom to pursue different goals or different levels of regulatory stringency. ${ }^{7}$

\section{Non-discrimination requirements}

Among the most basic principles of policed decentralization is the national treatment principle, which implies as a corollary the most-favored nation principle. Put simply, national treatment forbids regulators from discriminating against foreign firms by imposing greater burdens on them than on domestic firms.

The wisdom of this non-discrimination requirement is obvious. Whatever the justification for a particular regulation, there can be no justification for exempting domestic firms from the need to comply. Such favoritism toward domestic firms instead affords virtually conclusive evidence of capture or bureaucratic indifference, most probably the former, raising the costs of foreign suppliers relative to domestic competitors and thus having effects similar to traditional trade protection.

Equally clearly, however, a non-discrimination requirement falls far short of eliminating all of the undesirable costs of regulatory heterogeneity in the trading system. With reference to the typology of costs identified in Section 1, a non-discrimination requirement addresses only one category - added requirements for foreign firms. Avoidable costs of 'surprise', regulatory redundancy, loss of scale or input economies, information and conformity assessment may all persist despite national treatment, and thus efforts to remediate them through policed decentralization require additional measures.

\section{The sham principle and the obligation to give reasons}

An additional weapon against undesirable regulatory heterogeneity may be called the 'sham principle', under which the actions of regulators may be directly reviewed for improper motive. 'Sham' arises where the purported, high-minded objectives of regulation are found to be disingenuous and the real motive is found to be protectionist. The sham principle is related to non-discrimination principles in that evidence of discrimination is powerful evidence of sham, but it has the potential to reach non-discriminatory regulations as well when their true objective is to disadvantage foreign firms.

In an ideal world, the sham principle might police problems of capture quite effectively. But the world is far from ideal, and the sham principle in practice embroils dispute resolution authorities in the difficult task of ferreting out true motives. Often the motivation behind regulation is unclear, or it may be mixed - indeed, regulations are invariably the product of many agents acting together, and it may be the rare case in which they concur completely on the 'motive'. Further, even where the evidence of sham is

7 An extended review of each of the above-mentioned legal systems may be found in A. O. Sykes, above, ch. 4. 
compelling, it cun be exceedingly awhorand for dispure resolutian authorities to announce that officials from ane of the partics to the dispute hrve boen disingentuous in defense of their policies. Such a pronounoenent might even destroy the political equilibriura that allowed the introduction of policed decentralization in the first place. For these reasons, the shoun principle may not be involsed very often in practioe, provicularty in systems that lack a porkerful central authority to hold them togecher.

Even if dispure resolnsion authorinies ace trepidatious about invotoing the sharn principle, however, a mere requirement that national regulators offer a public defense of their policies can be valuabile. Imbarrassment is a nonurivial sanction for bureaucrats who have acted without carefully considering the implicacions of their sctions or invextizating their soundress. The prospect of being forced to offer a transparently disingenuous defense in public may also be enough in some cares to discourage regulators from going forwand with nationil regulations that result from capture and lack any principled justification. Lilkewise, even if formal sanctions do not materialize in the end, transparent insincerity may baing a reputational penalty to nations that act inappropriately and thus discourage same amount of misconduct. Whatever the limits of the sham principle, therefore, there is much to be said for a dispune resolution procedure that obligates nacions to give reasons for their actions, iderlly in a pablic forum.

\section{Trousparasey requinemrenses}

Transparency requirements indude a rumber of specifics, such as requirements for notice and comment prior to the issusnoe of new regulations, and requirements that regulations be published prompuly in an accessible fonum. Such requirements serie a useful function in remodiating a number of the casts idenrified pnevioutly.

Notice requirements directly address the problem of 'surprise' costs which, as noted, may tend to fall more heovily on foreign firms. If the notioe period is long enough and if notice is disseminated well enough, foreign finns can undertake new investrnents and retooling within the same time frome as comertic firms, and will not be disadvantaged by having to exit the market until their compliance measures are in place or by having to cede scale oconomies to the domestic first-movers.

Comment requirements serve a somewhat difierent function, sllowiog foreign firms to provide regulators wifh information bearing upon the wisdom of their proposed regulations, including information aboun the costs of compliance to foreigners. Where regulators might create unnecessary trade berriers due to their own limized or mistaben information, therefore, the opporrumity for foreign firms to comment may avoid the problem.

Finally, publication requirements reduce the costs to foreign firms of learning about regulations in foreign markets, and the costs of uncerminty about the possibility that sorne regulation may bave been orerlooked. It is 
especially helpful here if foreign firms can obwin all pertinent regulatory information from a single 'dearing house' agency or a single publication.

4. Geserality requivestens and the least restrictive means

Many regulatory objectives can be achieved in a variety of ways. The risk of insolvency for banks can be redaced through increasing the capical cushion or through reducing the riskiness of the asset portfolio. Food safery can be promoted through inspections of processing fecilities or through testing of the finished product. Fire safiecy cen be promoted through chemical treatmemt of otherwise fiammable materials or through the use of nonfinmmable materisls.

Reguiarions that insist upon one method to achieve a regulatory objective when other methods would serve equally well are usually undesirable. An optimal regulatory regime should, among other things, allow regulatory objectives to be achievod in the least-cost fastrion. And, when the objective can be achieved in a variety of ways, firns may well differ as to which method is the cheapest for them. This is expecially likely to be the case in international commeroe, where technologies and input prices will vary from counwy to country. Regulations that require their objectives to be achieved is limitad ways will thus tend to confer an uneconomic advantage on domestic firms, either because of capture or becnuse regulators draw on familiar experience as the basis for their regulations.

To combat this rendency, a system of policed decenoralization can require that regulations be draftod at the highest possible level of generality that suffices to meer regulatory goals. More or less equivalently, it can require that regulators consistendy employ the least restrictive means necessary to achieve their objectives.

Thus, for exmple, a regulation governing fire dours in commencial buildings might be drafted to require a certain 'burn-through' time far every doox, but should not be drafted to require the use of particular moterials or particular thicknesses where satisfactory perfurmance can be achieved without them. Similarty, a regulation concerning craissions from aubomobiles might be drafted to require that emissions of particular pollutants fall below cerrain levels, bur should nor be drafted to require the use of a paricular emissions control technology when others are available or may become available. The gentral principle that these examples illustrate is that product 'performance' regulations should almost always be used in preference to product 'desigo" regulntions.

Similar ideas make sense in sexvice sectors. If the goal of a banking regulation is to protect depositors and the monetary system against consequences of bank insolvency, for example, regulators ougbt to look to the overall riskiness of banking institutions in this regand and not simpity to the narrow question whether some small portion of the porffolio is invested in a paniculer risky asset. With regard to professional tioensing, regulators ought to rely more on general tesis of pertinent still and knowledge than an 
requirements that professionals attend one of a particular set of accredited institutions, or that their education encompass a particular curriculum.

Least restrictive means considerations also apply to conformity assessment. Requirements for testing at a particular laboratory or by a particular method can surely inflate the costs of conformity assessment unnecessarily. Indeed, requirements for testing or inspection by nationals of the importing nation, or on the soil of the importing nation, may well be unnecessary and invite abuse and capture.

Somewhat more controversially, the least restrictive means principle may weigh heavily in favor of labeling and disclosure regulation in preference to other forms of mandatory regulation in many circumstances, particularly where the regulation is not vital to an important health or safety objective. For example, many nations have required certain products to conform to particular designs or recipes to avoid consumer 'confusion' - 'cheese' might be required to have a certain fat content; 'pasta' might be required to be made from a particular flour; or 'beer' might be required to contain certain ingredients. ${ }^{8}$ Instead, it may well suffice for the label to disclose how a product is made, or that it departs from some conventional recipe.

All of these illustrations suggest how generality requirements and the least restrictive means principle can be particularly helpful in reducing the costs of regulatory redundancy or of measures to avoid it that sacrifice scale and input economies. By allowing firms to meet regulatory requirements in the cheapest way possible and, as a corollary, by recognizing that foreign suppliers of goods and services may already meet regulatory objectives albeit in a different way than domestic firms, these constraints on regulatory heterogeneity can greatly reduce its impact on trade withour requiring regulators to sacrifice any legitimate goal.

\section{The role of international standards and standard-setting institutions}

A number of international institutions develop and publish product standards. The International Organization for Standardization (ISO) has jurisdiction to address design, safety and quality concerns in product markets across the board, and publishes thousands of standards as a result of its work. The Codex Alimentarius focuses mainly on food safety issues. A miscellany of other entities with standard setting functions includes the - International Labor Organization, the International Telecommunications Union, the International Institute on Refrigeration, the International Commission on Illumination, and others. ${ }^{9}$ The European Union has its own 'international' bodies as well such as CEN, CENELEC and ETSI. ${ }^{10}$

Some movement toward international standards may also be seen in

8 Each of these examples is drawn from a modern case before the European Court of Justice - see

A. O. Sykes, above, 19-21.

9 Id. at 58-60.

${ }^{10} \mathrm{Id}$. at 89. 
service sectors. The recently concluded Basel Accord on bank capital requirements is illustrative, an accomplishment of negotiations among the member nations of the Basel Committee on Banking Supervision."

Typically, these institutions generate standards and guidelines for consideration by member states, with no legal obligation on the part of member states to rely on them or to implement them (although the Basel Accord is a notable exception, and European standards can become a 'safe harbor' for mutual recognition in connection with the modern 'essential requirements' directives ${ }^{12}$ ). Indeed, the standards and guidelines are often designed to assist private sector activities with no anticipation that they may bear on subjects of mandatory regulation.

Nevertheless, it is often desirable for regulators to use pertinent internationally-developed standards in their own national regulations. International standardization entities facilitate information exchange, and their collective judgments can avoid some of the errors that may result when national regulators act on the basis of their own more limited information. International standards also provide a reasonable set of regulatory options for poorer nations without resources to undertake their own scientific and regulatory studies. Finally, because international standard-setting institutions generally operate under a 'consensus' or super-majority voting requirement, the existence of an international standard can reflect a high level of agreement about its acceptability and the absence of a major constituency that would be disadvantaged by its implementation. Accordingly, unless a pertinent international standard is demonstrably inadequate to achieve a particular regulatory objective, its use will often constitute the least trade-disruptive method of achieving that goal. A system of policed decentralization can thus avoid unnecessary costs of regulatory heterogeneity through an obligation to employ international standards whenever they suffice to achieve the domestic objective.

Likewise, it is valuable for national regulators to participate actively in international standard-setting activities, even if those activities do not result in a standard because of insufficient consensus. At a minimum, high-level participation by regulators promotes the exchange of information and discourages trade impediments that might otherwise result from inadvertence or misleading information. International standards organizations can also serve to pool resources for scientific and technical work, and thereby overcome free-rider problems that may arise when nations may be tempted to wait and let other nations fund important scientific and technical studies. ${ }^{13}$

"See generally R. J. Herring \& R. E. Litan, Financial Regulation in the Global Economy (Brookings: 1995).

12 A. O. Sykes, above at 89.

${ }^{13}$ In this respect, international standards organizations can facilitate the attainment of what some have termed 'economies of scale' in regulation. See D. C. Esty, 'Revitalizing Environmental Federalism', 95 Mich. L. Rev. 570, 614-617. 
An obligation to support and participate in international standard setting, therefore, is also a valuable part of a system of policed decentralization.

\section{Mutual recognition, or 'close enough for government work'}

The pattern of regulation in the developed world exhibits some remarkable similarities. Whether the subject is bank solvency, professional licensing, food safety or auto emissions control, most governments of most developed countries tend to get involved in regulating, often with similar goals in mind.

Differences in regulatory emphasis and stringency are nevertheless common, and in many cases justifiable for reasons relating to tastes, incomes or the other factors discussed earlier. But these differences in emphasis and stringency may be minor, to the point that goods or services produced in one jurisdiction will come reasonably close to satisfying the legitimate regulatory objectives of another even if not perfectly satisfying those objectives.

When such circumstances arise, it may well make sense for nations to agree to compromise their regulatory objectives modestly in the interests of avoiding the various trade impediments from regulatory heterogeneity identified earlier. Thus, although German insurance regulators might prefer that French insurance companies hold slightly larger reserves, and Japanese meat inspectors might prefer that American meat packing plants be inspected slightly more often, the costs of ignoring these differences in judgment may plausibly be small, and far less than the gains from allowing firms in each country to export freely without the need to adjust their operations to comply with the importing country's own regulations.

The principles of policed decentralization discussed above will not ensure this outcome, of course, because by hypothesis the jurisdictions in question exhibit bona fide differences of opinion over the appropriate regulatory standards to apply. There is no discrimination, no sham or disingenuous policy, no consensus on an international standard, and no sense in which regulators are using unduly restrictive means to achieve their goals. Rather, the problem lies in the fact that the difference of opinion over the appropriate degree of regulation can impose costs on international commerce (and domestic consumers) that are out of proportion to the importance of the differences in substantive regulation. Under these conditions, the best option may be for regulators to agree to disagree, while opening their markets to goods and services that comply with the applicable regulations in their country of origin. Such a policy may be accompanied in appropriate circumstances with disclosure requirements that inform consumers of the differences between imported and domestic goods and services and allowing them to make an informed choice of which to buy. Such a policy has come to be known as 'mutual recognition'. Its great virtue, from a trade standpoint, is that it more or less exempts foreign suppliers from regulations in the importing country, and the attendant costs of compliance. 
Plainly, mutual recognition is more likely to be attractive where the preexisting differences in policy across jurisdictions are modest, and do not implicate highly sensitive issues. Thus, it is more likely to be attractive between two countries at a comparable level of development and per capita income than, for example, between a developed nation and an undeveloped nation. It is also more likely to be attractive where serious issues of human health and safety are not in play.

Beyond these rather obvious considerations, it is difficult to articulate any concrete principle as to when mutual recognition ought be afforded, certainly not a principle that is susceptible to administration by a third-party dispute resolution process. Even so, one might expect mutual recognition to arise by mutual agreement whenever the trade benefit - and thus the political pressure for mutual recognition as a market-opening initiative - is great, and whenever the perceived violence to regulatory objectives - and thus the political opposition to mutual recognition - is small.

Further, even if it is impossible to write down a general legal rule that will compel mutual recognition under appropriate circumstances, international agreements and institutions can nevertheless facilitate it in important ways. The natural exchange of information that occurs as a result of trade negotiations and participation in international standardization activities can raise the comfort level of regulators and their constituencies about the consequences of mutual recognition. And, just as the obligation to give reasons in defense of regulatory policies can discourage indifference, incompetence and capture in general, so can an obligation to give reasons for refusing mutual recognition increase the costs to governments of insisting on adherence to the letter of their regulatory policies without good reason.

\section{WHAT ROLE FOR REGULATORY HARMONIZATION?}

Suppose, counterfactually, that the trading community had faithfully implemented the principles of policed decentralization set forth above in all areas where trade impediments arise because of regulatory heterogeneity, and had extended mutual recognition wherever the remaining regulatory differences were modest enough that the benefits of increased trade seemed to outweigh the economic or political costs of regulatory compromise. What would remain to be done to achieve the benefits of a liberal trading order without jeopardizing the ability of nations to take account of legitimate differences between themselves? The answer, I suggest, is very little.

The principles of policed decentralization would have ensured that regulatory differences did not arise because of bureaucratic indifference, inadequate information, or the use of unduly restrictive means to achieve regulatory goals. Whatever trade barriers remained would then inhere in the fact that different jurisdictions had chosen to regulate more stringently in some areas, and had declined to extend mutual recognition. 
To be sure, some of the resistance to mutual recognition might well reflect capture by politically powerful industry constituencies rather than a sensible refusal based on the importance of respecting differences in tastes, incomes, and the like. But harmonization is not the answer to this problem, either as a practical matter or from a normative perspective. The same interest groups that block mutual recognition could be expected to block harmonization as well. Further, to the extent that differences in national regulatory policy had any foundation in legitimate rather than protectionist considerations, harmonization would seem inferior to mutual recognition in an ideal world.

This completes the essential argument. As a normative matter, the observation that regulatory differences are often justifiable on principled grounds establishes that harmonization is not in general ideal. Rather, the ideal world is one in which regulatory heterogeneity is limited to those differences which reflect bona fide differences in tastes, incomes and other miscellaneous factors. And even then, the costs of heterogeneity to trade must be balanced against its benefits - sometimes the costs may too great to justify imposing domestic regulatory policy on foreign suppliers. Fully implemented principles of policed decentralization, coupled with mutual recognition where regulatory differences are more troublesome than they are worth, can in principle achieve the ideal objective. Harmonization is unnecessary at best, and counterproductive at worst.

To these objections to harmonization, one must add that internationally harmonized regulations are likely to be more rigid than national regulations, simply because the consensus required to create them may not exist to change them. They may be more likely to perpetuate a policy that is revealed to be misguided by subsequent developments, therefore, and less likely to adapt sensibly to changes in technology.

As a positive matter, these observations provide considerable reason to doubt that harmonization will often be pursued in the trading community. ${ }^{14}$ Although I would not contend that the international community always converges on what is efficient from an economic standpoint (it self-evidently does not), the fact that most of the unjustifiable trade impediments can be eliminated without harmonization leads one to doubt that harmonization will often have much of a political constituency.

I conclude with two caveats. First, there are no doubt a few instances in which there can be no principled reason for governments to follow different regulatory policies. When governments become involved with matters of

14 To be sure, Europe has undertaken some efforts at harmonization as defined here under the 'old approach' to the approximation of national regulations. But successful efforts under the old approach were few and it was ultimately abandoned in favor of the 'new approach' and its 'essential requirements' directives. In the terminology of this paper, the 'new approach' is a blend between the reference to international standards principle of policed decentralization, and mutual recognition. For further discussion of the European experience, see A. O. Sykes, above at 87-92, and sources cited therein. 
technological compatibility, for example, such as television broadcast formats, it may well be desirable for all nations to embrace the same standard (although it may not if there is uncertainty as to which standard is best). Here, international agreement to follow the same policy may be warranted, and 'harmonization' is useful.

Second, when matters of domestic regulation implicate important crossborder spillovers (chlorofluorocarbons and the ozone layer, for example), it is undeniable that international co-operation is desirable to address the problem. In suggesting that harmonization is not ideal, therefore, I do not mean to suggest that international co-operation on such matters is counterproductive, or to deny that co-operation might occasionally result in a uniform policy applicable to everyone (such as a ban on CFCs). But that outcome would simply be another illustration of the above-noted possibility - in a few cases, it is desirable for every government to follow exactly the same policy. The limited utility of regulatory harmonization owes precisely to the fact that this situation is very much the exception rather than the rule. 